\title{
(2) OPEN ACCESS \\ Cardiovascular disease risk in immune-mediated inflammatory diseases: recommendations for clinical practice
}

\author{
Rabia Agca () , ${ }^{1}$ Yvo Smulders, ${ }^{2}$ Michael Nurmohamed ${ }^{1}$
}

- Additional material is published online only. To view please visit the journal online (http://dx.doi.org/10.1136/ heartjnl-2019-316378).

${ }^{1}$ Rheumatology, Amsterdam UMC and Reade, Amsterdam, Noord-Holland, The Netherlands ${ }^{2}$ Internal Medicine, Amsterdam UMC, Amsterdam, NoordHolland, The Netherlands

\section{Correspondence to}

Dr Rabia Agca, Rheumatology, Amsterdam UMC and Reade,

Amsterdam, Noord-Holland, Netherlands;

r.agca@amsterdamumc.nl
Check for updates

(C) Author(s) (or their employer(s)) 2021. Re-use permitted under CC BY-NC. No commercial re-use. See rights and permissions. Published by BMJ.

To cite: Agca R, Smulders $Y$, Nurmohamed M. Heart Epub ahead of print: [please include Day Month Year]. doi:10.1136/ heartjnl-2019-316378

\section{INTRODUCTION}

Immune-mediated inflammatory diseases (IMIDs) comprise a wide range of conditions of which rheumatoid arthritis (RA), spondyloarthritis (SpA) and inflammatory bowel disease (IBD; ie, Crohn's disease and ulcerative colitis) are most common (table 1, table 2). SpA consists of a range of diseases, including ankylosing spondylitis (AS), psoriatic arthritis (PsA), reactive arthritis, spondylitis associated with IBD and undifferentiated SpA. ${ }^{1}$ As data regarding cardiovascular disease (CVD) risk are mainly available for RA, AS, PsA, severe psoriasis and IBD, we will focus on these conditions.

\section{CVD RISK IN CHRONIC INFLAMMATORY DISEASES}

IMIDs are associated with increased mortality when compared with the general population (table 1). Reported standardised mortality ratios (SMRs) range from 0.9 to 2.7 for RA, from 1.6 to 1.9 for $\mathrm{SpA}$, and from 1.2 to 1.5 for IBD. ${ }^{23}$ Majority of these excess deaths are caused by CVD, at least in patients with RA and SpA. ${ }^{4}$ A meta-analysis of 14 observational studies, including 40000 patients with RA, showed an age-adjusted and sex-adjusted relative risk (RR) of 1.48 (95\% CI 1.36 to 1.62 ) for a first CVD event, mainly driven by an increased risk of myocardial infarction (MI) and stroke. ${ }^{5}$ The available studies report an HR of $1.36(95 \%$ CI 1.13 to 1.65$)$ in patients with AS and 1.24 (95\% CI 1.03 to 1.49 ) in patients with PsA for major atherosclerotic events after adjustment for traditional cardiovascular (CV) risk factors. ${ }^{67}$ This also applies to patients with severe psoriasis (HR 1.42, $95 \%$ CI 1.17 to 1.73 ). The association between IBD and CVD mortality is less consistent than for RA and SpA. A meta-analysis from 2017 showed an RR of 1.24 (95\% CI 1.14 to 1.36) for MI and stroke in IBD, which was more pronounced in women (adjusted RR 1.35 (95\% CI 1.21 to 1.53 ) vs 1.19 (95\% CI 1.03 to 1.38 ) in men). ${ }^{8}$ Furthermore, younger patients had a relatively higher CVD risk when compared with patients who were 50 years or older (RR 1.35 (95\% CI 1.06 to 1.74) vs 1.27 (95\% CI 1.13 to 1.42$)) .{ }^{8}$ Similar numbers were described in a meta-analysis from $2018 .{ }^{9}$ However, there are also studies that have found no association between IBD and CVD. ${ }^{8}$ More importantly, the increased CVD risk described above does not appear to translate into an increased mortality, as reported SMRs for CVD are 0.9 (95\% CI 0.8 to 1.02) for ulcerative colitis and 1.0 (95\% CI 0.88 to 1.13) for Crohn's disease. $^{2}$

\section{Learning objectives}

- To create awareness of the increased cardiovascular disease risk in immune-mediated inflammatory diseases.

- To understand the aetiology of increased cardiovascular disease risk in immune-mediated inflammatory diseases, in particular the independent roles of traditional cardiovascular risk factors and chronic inflammation.

- To realise the importance of treatment of both cardiovascular risk factors as well as optimal anti-inflammatory therapy to reduce cardiovascular disease risk.

In addition to the risk of atherosclerotic CVD, IMIDs are also linked to an increased risk of other types of CVD, such as heart failure, arrhythmias, deep venous thrombosis and pulmonary embolism. A more indepth description of these risk factors can be found in Agca et al. ${ }^{10}$

\section{CVD RISK FACTORS IN IMIDS \\ Smoking}

Smoking is an acknowledged independent contributor to CVD risk. Smoking is an environmental risk factor for the development of RA and is associated with increased disease severity. ${ }^{11}$ Patients with RA are more often smokers when compared with controls. ${ }^{12}$ However, the impact of smoking on CVD risk in RA is less clear. Only one study reported a weaker association between smoking and CVD in patients with RA when compared with controls. ${ }^{13}$ Data regarding smoking in AS and PsA are conflicting, with studies reporting both increased and lower prevalence of smoking in these patients. ${ }^{14-17}$ Smoking is not associated with the development of AS, but it does influence clinical and functional outcomes. ${ }^{18}$ However, smoking is an independent risk factor for psoriasis development. Interestingly, smoking is associated with the development and severity of Crohn's disease, but not with ulcerative colitis. ${ }^{19}$ In contrast, there are suggestions for a protective effect in patients with ulcerative colitis, with less severe disease, lower rates of anti-inflammatory therapy and colectomy in smokers. ${ }^{19}$ The reason for this disparity is unknown. Patients with IMIDs are recommended to stop smoking, similar to the general population and according to current CVD prevention strategies. 
Table 1 Main characteristics of the most common immune-mediated inflammatory diseases

\begin{tabular}{|c|c|c|c|c|c|}
\hline \multirow[b]{3}{*}{$\begin{array}{l}\text { Main clinical } \\
\text { manifestations* }\end{array}$} & \multirow[b]{2}{*}{ Rheumatoid arthritis } & \multicolumn{2}{|l|}{ Spondyloarthritis } & \multicolumn{2}{|l|}{ Inflammatory bowel disease } \\
\hline & & Ankylosing spondylitis & Psoriatic arthritis & Crohn's disease & Ulcerative colitis \\
\hline & $\begin{array}{l}\text { Arthritis } \geq 3 \text { joints. } \\
\text { Elevated CRP and ESR. } \\
\text { Presence of RF and anti-CCP } \\
\text { antibodies. } \\
\text { Male:female } 1: 2-3 \text {. } \\
\text { Onset in fourth, fifth or sixth } \\
\text { decade. }\end{array}$ & $\begin{array}{l}\text { Arthritis of SI and axial joints } \\
\text { and ankylosis of spinal column. } \\
\text { Association with HLA-B27 } \\
\text { genotype. } \\
\text { Elevated CRP and ESR in } \\
\text { approximately } 50 \% \text {. } \\
\text { Male:female 3:1. } \\
\text { Onset generally before the age } \\
\text { of } 30 t .\end{array}$ & $\begin{array}{l}\text { Inflammation of distal } \\
\text { joints (DIPs > PIPs). } \\
\text { Psoriasis. } \\
\text { Slight predominance in } \\
\text { men. } \\
\text { Onset } 45-54 \text { years. }\end{array}$ & $\begin{array}{l}\text { Involvement of any } \\
\text { portion of the GI tract. } \\
\text { Transmural } \\
\text { inflammation. } \\
\text { Arthritis } \sim 6 \%-14 \% \text {. } \\
\text { Slight predominance in } \\
\text { women. } \\
\text { Onset commonly }<30 \\
\text { years, second peak in } \\
\text { women } 60-70 \text { years. }\end{array}$ & $\begin{array}{l}\text { Colon involvement. } \\
\text { Inflammation of mucosal } \\
\text { layer. } \\
\text { Arthritis } \sim 6 \%-14 \% . \\
\text { Slight predominance } \\
\text { in men. } \\
\text { Onset } 30-40 \text { years. }\end{array}$ \\
\hline Treatment options & $\begin{array}{l}\text { NSAIDs. } \\
\text { Oral/intra-articular } \\
\text { glucocorticosteroids. } \\
\text { DMARDs. } \\
\text { Biologicals. }\end{array}$ & $\begin{array}{l}\text { NSAIDs. } \\
\text { Oral/intra-articular } \\
\text { glucocorticosteroids. } \\
\text { Biologicals. }\end{array}$ & $\begin{array}{l}\text { NSAIDs. } \\
\text { Oral/intra-articular } \\
\text { glucocorticosteroids. } \\
\text { DMARDs. } \\
\text { Biologicals. }\end{array}$ & $\begin{array}{l}\text { Salicylates. } \\
\text { Oral } \\
\text { glucocorticosteroids. } \\
\text { DMARDs. } \\
\text { Biologicals. } \\
\text { Operative. }\end{array}$ & $\begin{array}{l}\text { Salicylates. } \\
\text { Oral glucocorticosteroids. } \\
\text { DMARDs. } \\
\text { Biologicals. } \\
\text { Operative. }\end{array}$ \\
\hline CVD risk & $\begin{array}{l}\text { Twofold increased mortality } \\
\text { rate comparable with diabetes. } \\
\text { CVD main cause of death, } \\
\text { mainly due to atherosclerotic } \\
\text { disease. }\end{array}$ & $\begin{array}{l}\text { Increased mortality rate. } \\
\text { CVD main cause of death. } \\
\text { Both atherosclerotic disease and } \\
\text { specific cardiac manifestations. }\end{array}$ & $\begin{array}{l}\text { Increased mortality rate. } \\
\text { Increased prevalence } \\
\text { of MI. }\end{array}$ & $\begin{array}{l}\text { Increased CVD risk, } \\
\text { but not increased CVD } \\
\text { mortality. }\end{array}$ & $\begin{array}{l}\text { Increased CVD risk } \\
\text { but not increased CVD } \\
\text { mortality. }\end{array}$ \\
\hline
\end{tabular}

${ }^{*}$ This list includes the main clinical manifestations of IMIDs, but it is in no means a complete list of symptoms and IMIDs commonly have overlapping characteristics. tOften delayed diagnosis due to lack of disease knowledge and misdiagnosis, especially in women.

anti-CCP, anticitrullinated protein antibody; CRP, C reactive protein; CVD, cardiovascular disease; DIPs, distal interphalangeal joints; DMARDs, disease-modifying antirheumatic drugs; ESR, erythrocyte sedimentation rate; GI, gastrointestinal; HLA-B27, human leucocyte antigen B27; IMIDs, immune-mediated inflammatory diseases; MI, myocardial infarction; NSAIDs, non-steroidal anti-inflammatory drugs; PIPs, proximal interphalangeal joints; RF, rheumatoid factor; SI, sacroiliac.

\section{Hypertension}

Studies regarding hypertension and its contribution to CVD risk are conflicting in RA, possibly due to under-recognition of hypertension in RA. ${ }^{12} 20$ The same applies to patients with AS, for which studies report contrasting results. ${ }^{21}$ In PsA and

Table 2 Glossary

\begin{tabular}{|c|c|}
\hline & Definition \\
\hline $\begin{array}{l}\text { Immune-mediated } \\
\text { inflammatory diseases }\end{array}$ & $\begin{array}{l}\text { A group of diseases characterised by dysregulation of the immune system } \\
\text { leading to chronic inflammation in certain tissues. }\end{array}$ \\
\hline Rheumatoid arthritis & $\begin{array}{l}\text { Chronic systemic inflammatory disease typically affecting the peripheral } \\
\text { joints, but involvement of other organs and tissues is also seen. Positive } \\
\text { rheumatoid factor and anticitrullinated peptide antibodies in } 75 \%-80 \% \text {. }\end{array}$ \\
\hline Spondylarthropathies & $\begin{array}{l}\text { A group of diseases, including ankylosing spondylitis, psoriatic arthritis, } \\
\text { reactive arthritis and spondylitis associated with inflammatory bowel } \\
\text { disease, characterised by inflammation of the axial and/or peripheral joints, } \\
\text { dactylitis and enthesitis. }\end{array}$ \\
\hline Ankylosing spondylitis & $\begin{array}{l}\text { Inflammation of the spine (sacroiliitis) with insidious chronic back pain } \\
\text { usually presenting before the age of } 45 \text {, with or without arthritis of the } \\
\text { peripheral joints, enthesitis, dactylitis, uveitis, psoriasis and inflammatory } \\
\text { bowel disease. Human leucocyte antigen B27 present in } 80 \%-95 \% \text {. }\end{array}$ \\
\hline Psoriatic arthritis & $\begin{array}{l}\text { Inflammation of joints associated with psoriasis, with or without axial } \\
\text { disease, enthesitis, tenosynovitis, dactylitis and nail lesions. }\end{array}$ \\
\hline $\begin{array}{l}\text { Inflammatory bowel } \\
\text { disease }\end{array}$ & $\begin{array}{l}\text { A group of diseases comprising Crohn's disease and ulcerative colitis. } \\
\text { Crohn's disease can involve the whole gastrointestinal tract from the } \\
\text { mouth to the perianal area. Ulcerative colitis affects the colon. }\end{array}$ \\
\hline Interleukin 6 & Cytokine involved in inflammation. \\
\hline $\begin{array}{l}\text { Tumour necrosis factor } \\
\text { alpha }\end{array}$ & Cytokine involved in inflammation. \\
\hline $\begin{array}{l}\text { Conventional disease- } \\
\text { modifying antirheumatic } \\
\text { drugs }\end{array}$ & $\begin{array}{l}\text { Immunoregulatory or immunosuppressive agents including methotrexate, } \\
\text { hydroxychloroquine, leflunomide and azathioprine. }\end{array}$ \\
\hline $\begin{array}{l}\text { Biologic disease-modifying } \\
\text { antirheumatic drugs }\end{array}$ & $\begin{array}{l}\text { Immunoregulatory or immunosuppressive agents including etanercept, } \\
\text { adalimumab, infliximab, rituximab, tocilizumab, abatacept and tofacitinib. }\end{array}$ \\
\hline $\begin{array}{l}\text { Non-steroidal anti- } \\
\text { inflammatory drugs }\end{array}$ & Inhibitors of cyclo-oxygenase with anti-inflammatory effects. \\
\hline
\end{tabular}

severe psoriasis, the prevalence of hypertension is increased. ${ }^{22} 23$ Interestingly, patients with IBD have lower rates of hypertension when compared with the general population. ${ }^{24}$ Overall, there is no evidence for a different approach in IMIDs compared with the general population regarding treatment of hypertension to reduce CVD risk. However, studies do report an undertreatment of hypertension in these patients. ${ }^{1725}$

\section{Dyslipidaemia}

Lipids are an interesting area of research in IMIDs as they act differently under inflammatory circumstances compared with the general population. In patients with RA with active disease serum low-density lipoprotein (LDLc) and total cholesterol (TC) levels are low, while CVD risk is increased. ${ }^{26}$ The exact cause of this is unclear. A possible explanation is that patients with active disease have decreased high-density lipoprotein (HDLc) levels. In addition, inflammation negatively affects the antiatherogenic properties of HDLc (eg, by reducing cholesterol efflux and antioxidant capacity) and LDLc, possibly causing an increased CVD risk. In AS, PsA, severe psoriasis and IBD lipid levels are affected in a similar pattern by disease activity, that is, lower lipid levels, while their CVD risk is increased. ${ }^{21} 24$ For IBD, this appears to be more pronounced in Crohn's disease than in ulcerative colitis. ${ }^{24}$ Interestingly, lipid particles themselves are capable of influencing inflammatory pathways. HDLc is suggested to be an inflammatory modifier, as it is able to influence $\mathrm{T}$ cell lymphocyte and macrophage interaction. ${ }^{27}$ However, the clinical relevance of short-term changes in lipids for $\mathrm{CV}$ outcomes in patients with IMIDs remains to be 
Table 3 Prevalence of CVD risk factors in immune-mediated inflammatory diseases

\begin{tabular}{llllll}
\hline & & Spondyloarthritis & & \multicolumn{2}{l}{ Inflammatory bowel disease } \\
\hline Smoking & Rheumatoid arthritis & Ankylosing spondylitis & Psoriatic arthritis & UC & CD \\
Hypertension & Increased & Conflicting data & Conflicting data & $\begin{array}{l}\text { Increased } \\
\text { UC:CD 1:2 }\end{array}$ & Increased \\
UC:CD 1:2 & Decreased \\
Dyslipidaemia* & $\begin{array}{l}\text { Conflicting data, probably } \\
\text { under-recognised and } \\
\text { undertreated }\end{array}$ & Conflicting data & Increased & Decreased & Increased \\
Obesity & Increased & Increased & Increased & Increased & Decreased \\
Physical inactivity & Increased & Decreased & Increased & Decreased & Increased \\
Diabetes/insulin resistance & Increased & Increased & Increased & Increased & Increased \\
\hline
\end{tabular}

*'Lipid paradox' with lower lipids during active disease while cardiovascular disease risk is increased.

CD, Crohn's disease; CVD, cardiovascular disease; UC, ulcerative colitis.

determined. Anti-inflammatory therapy generally normalises lipid levels and function, which leads to increases in TC and LDLc. However, this does not translate into an increased CVD risk and should be regarded as a normalisation of lipid levels. With regard to dyslipidaemia treatment statins are just as effective in reducing CVD risk in IMIDs as in the general population. ${ }^{28}$ In addition, lipid levels should be assessed during stable disease or disease remission as inflammation affects lipid levels and could lead to an inaccurate CVD risk prediction during active disease. The TC to HDLc ratio correlates better with $C$ reactive protein (CRP) and is more stable, making it more appropriate for CVD risk prediction in patients with IMIDs. ${ }^{29}$

\section{Diabetes}

There are conflicting reports regarding the prevalence of type 2 diabetes mellitus (DM) in IMIDs. In RA, the prevalence of insulin resistance (IR) appears to be increased when compared with controls (54\% vs $40 \%-45 \%) .{ }^{30}$ Furthermore, IR has been associated with increased CRP, erythrocyte sedimentation rate, interleukin 6 and tumour necrosis factor alpha in RA. ${ }^{30}$ Similarly, IR and DM prevalence is increased in PsA and psoriasis (11.3\% vs $7.3 \%)$, possibly due to a higher prevalence of obesity in these patients. ${ }^{6}{ }^{23}$ This is not observed in AS. ${ }^{23}$ In IBD, an increased risk of DM is reported when compared with controls (Crohn's disease HR 2.395 vs 1.563 ; ulcerative colitis HR 1.589 vs 1.020 , $\mathrm{p}<0.05){ }^{24}$ The underlying causal mechanism for this phenomenon is unknown. Patients with IMIDs should be monitored regularly for DM.

\section{Diet}

In the general population, the Mediterranean diet reduces the occurrence of new CV events. ${ }^{24} 31$ In patients with RA this diet seems to have positive effects on disease activity, which could translate into a lower CVD risk through reduction of inflammation. ${ }^{32}$ In IBD, high-fat diets have been shown to increase disease flares, while diets with high fibre content, low fat and low simple carbohydrates have been associated with a decrease in the number of flares and inflammatory markers and an increase in remission rates. Whether certain dietary modifications reduce the risk of CVD in patients with IMIDs is not clear. Following a healthy diet according to national guidelines is recommended for patients with IMIDs.

\section{Body weight and body composition}

It is unclear whether body mass index (BMI) differs between patients with RA and the general population. However, patients with RA have more body fat and less lean body mass for a given BMI when compared with controls. ${ }^{33}$ Furthermore, body composition appears to be affected by disease activity. Patients with RA with disease flares have a lower BMI in combination with low lean body
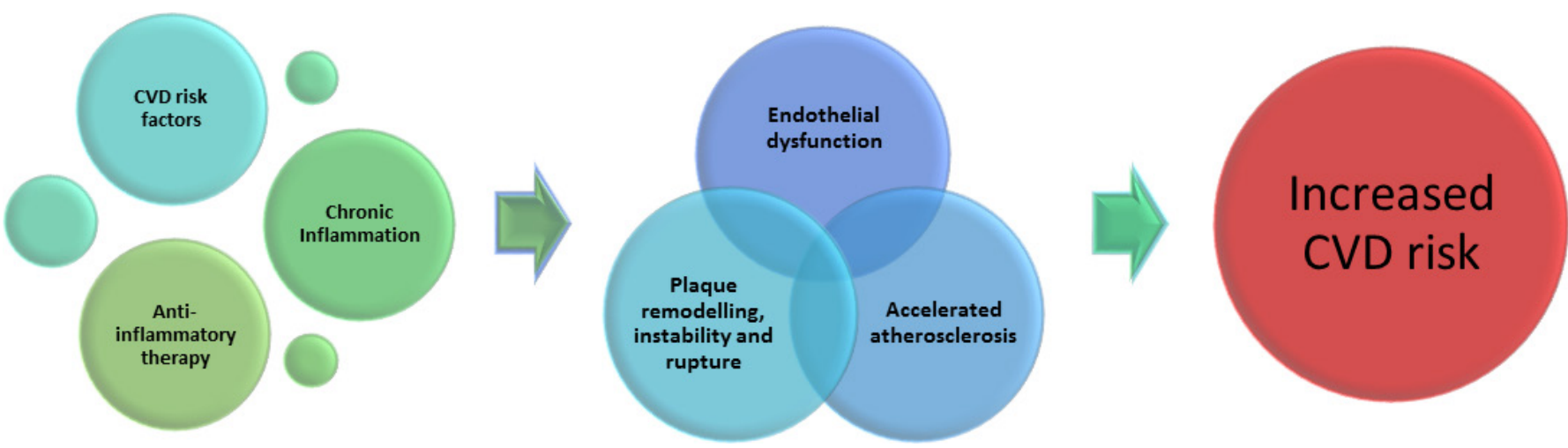

Figure 1 Contributors to cardiovascular disease (CVD) risk in immune-mediated inflammatory diseases. 


\begin{tabular}{lll}
\hline Table 4 & Effect of anti-inflammatory medications on cardiovascular risk \\
\hline Anti-inflammatory agent & & Cardiovascular events \\
\hline csDMARDs & $\begin{array}{l}\text { Methotrexate, leflunomide, sulfasalazine } \\
\text { and hydroxychloroquine }\end{array}$ & Decreased \\
tsDMARDs & $\begin{array}{l}\text { Baricitinib, tofacitinib and upadacitinib } \\
\text { bDMARDs }\end{array}$ & $\begin{array}{l}\text { Unknown } \\
\text { (anti-TNF), golimumab (anti-TNF), } \\
\text { infliximab (anti-TNF), tocilizumab (anti- } \\
\text { IL-6), sarilumab (anti-IL-6), abatacept } \\
\text { (anti-T cell costimulation), rituximab } \\
\text { (anti-B cell) and anakinra (anti-IL-1) }\end{array}$ \\
\hline NSAIDs & $\begin{array}{l}\text { Diclofenac, ibuprofen, naproxen, } \\
\text { meloxicam, nabumetone, celecoxib and } \\
\text { etoricoxib }\end{array}$ & $\begin{array}{l}\text { Conflicting data, possibly } \\
\text { increased }\end{array}$ \\
Glucocorticosteroids & $\begin{array}{l}\text { Prednis(ol)one, methylprednisolone, } \\
\text { triamcinolone and dexamethasone }\end{array}$ & $\begin{array}{l}\text { Increased, but dose- } \\
\text { dependent and duration- } \\
\text { dependent }\end{array}$ \\
\hline
\end{tabular}

bDMARDs, biologic disease-modifying antirheumatic drugs; csDMARDs, conventional synthetic diseasemodifying antirheumatic drugs; IL, interleukin; NSAIDs, non-steroidal anti-inflammatory drugs; TNF, tumour necrosis factor; tsDMARDs, targeted synthetic disease-modifying antirheumatic drugs.

mass (ie, rheumatoid cachexia), which disappears after treatment. ${ }^{34} 35$ This low BMI (and lean body mass) has been associated with increased CVD risk in RA. ${ }^{20}$ In AS and PsA, an increased BMI correlates with worse disease outcomes and obesity is common in PsA and psoriasis. ${ }^{22} 36$ In Crohn's disease, lower BMI, lean body mass and bone mineral density are seen during disease flares when compared with patients with ulcerative colitis and healthy controls. ${ }^{37}$ This is observed more frequently in men than in women with Crohn's disease. ${ }^{37}$ However, patients with obesity appear to have an increased risk of developing Crohn's disease, but not ulcerative colitis. ${ }^{38}$ Furthermore, obese patients with Crohn's disease more often have disease flares than patients with a normal body weight. ${ }^{38}$ It is important to recognise that $\mathrm{BMI}$ is not accurate for CVD risk estimation in patients with IMIDs.

\section{Physical activity}

Physical activity is known to reduce CVD risk in the general population. ${ }^{39}$ On average, patients with inflammatory condition are less active, which has been associated with a worse CVD risk profile. ${ }^{4041}$ In patients with RA, beneficial effects of exercise on vascular function, cardiorespiratory fitness and CVD risk have been described, already after 3 months. ${ }^{42}$ Furthermore, CRP levels are reduced in patients with RA after 6 months of exercise therapy, possibly due to reduction in body fat. ${ }^{43}$ In addition, resistance training has been shown to increase lean body mass in RA. ${ }^{44}$ Similarly, patients with AS and PsA with active disease are less physically active than controls, which has been associated with a worse prognosis and premature death. ${ }^{21}$ For AS, physical training is the cornerstone of treatment, positively affecting disease activity and presumably simultaneously decreasing CVD risk. ${ }^{45}$ In IBD, the effects of exercise on the disease course are unknown, but patients do seem to benefit in terms of fitness, body composition and quality of life. ${ }^{46}$ In all patients with IMIDs, exercise has beneficial effects and should be encouraged. To date there are no studies describing the adverse effects of physical activity in these patients. ${ }^{44}$

\section{Psychosocial factors}

Depression and socioeconomic deprivation are more prevalent in patients with IMIDs. Both have been associated with the development of CVD and a worse prognosis in previous studies. These factors are of importance in the assessment and management of CVD risk and are possible barriers to optimal treatment of patients.

\section{CHRONIC SYSTEMIC INFLAMMATION}

Although patients with IMIDs generally have an increased prevalence of traditional CVD risk factors, the excess CVD risk and mortality cannot be explained by these risk factors alone (table 3). IMIDs are characterised by ongoing systemic inflammation, which has been linked to accelerated atherosclerosis. ${ }^{47}$

In RA, studies have demonstrated an independent association between inflammation and CVD, which persisted after adjustment for traditional CVD risk factors. ${ }^{48}$ In this study, the CVD risk in RA was equal to the CVD risk in DM. ${ }^{48}$ Another study has demonstrated that a higher inflammatory burden and an increased number of disease flares are associated with more new CVD events in RA. ${ }^{49}$ Chronic inflammation enhances endothelial dysfunction and induces maladaptive remodelling of the vascular wall and influences the composition of an atherosclerotic plaque, resulting in plaque instability and rupture (figure 1). In line with this, in patients with RA, coronary plaques are more frequent, more severe and more prone to rupture. It is currently less clear to what extent inflammation affects CVD risk in AS, PsA or psoriasis, but it is conceivable that the $\mathrm{CV}$ effects of inflammation in these patients are similar to that in RA.

In IBD, there are a limited number of studies available about the effects of disease flares or inflammation on CVD risk. The available epidemiological studies and studies on carotid intima media thickness (cIMT), wall stiffness and endothelial function show results similar to that in RA, with increased cIMT and endothelial dysfunction in patients with higher CRP levels. ${ }^{50}$

Anti-inflammatory therapy, such as conventional and biologic disease-modifying antirheumatic drugs (table 4), has been shown to reduce CVD risk in RA and SpA, with beneficial effects on cIMT, lipid profile and IR. ${ }^{50}$ An exception to this might be glucocorticosteroids, which have been associated with a dose-dependent increase in CVD risk. ${ }^{24} 50$ However, the reduction of high-grade inflammation may counter this effect in patients with IMIDs. In addition, treatment with non-steroidal anti-inflammatory drugs (NSAIDs) in combination with regular exercise is the cornerstone of treatment for AS, but NSAID side effects might adversely affect CVD risk, especially in young patients. However, the exact CVD effects of NSAIDs in AS are unknown as they also significantly improve mobility. The CVD effects of biologic disease-modifying 
Key messages

- Optimal anti-inflammatory treatment is necessary to reduce cardiovascular disease (CVD) risk in immune-mediated inflammatory diseases (IMIDs).

- Lifestyle interventions according to national guidelines, such as smoking cessation, exercise to increase physical fitness and lean body mass, and healthy diets, are recommended.

- Optimal treatment of CVD risk factors, including dyslipidaemia and hypertension, according to existing national guidelines is as important as lowering inflammation to reduce CVD risk in IMIDs.

- Treatment targets for lowering low-density lipoprotein and blood pressure should be according to national guidelines.

- Statins are as effective in lowering lipid levels in patients with IMIDs as in the general population.

- Patients with IMIDs should be screened for diabetes.

- For rheumatoid arthritis a multiplication factor should be applied to CVD risk prediction algorithms.

- For other IMIDs a risk assessment according to existing algorithms is recommended as there is insufficient evidence about other methods.

\section{CME credits for Education in Heart}

Education in Heart articles are accredited for CME by various providers. To answer the accompanying multiple choice questions (MCQs) and obtain your credits, click on the 'Take the Test' link on the online version of the article. The MCQs are hosted on BMJ Learning. All users must complete a one-time registration on BMJ Learning and subsequently log in on every visit using their username and password to access modules and their CME record. Accreditation is only valid for 2 years from the date of publication. Printable CME certificates are available to users that achieve the minimum pass mark.

antirheumatic drugs in IBD have not yet been studied.

\section{APPROACH TO MANAGEMENT OF CVD RISK IN PATIENTS WITH IMIDS IN DAILY CLINICAL PRACTICE}

IMIDs are prevalent conditions (ie, 5\%-7\%) (1) $^{51}$ worldwide requiring appropriate risk assessment and management strategies to reduce the burden on healthcare systems, but more importantly to improve survival and quality of life of affected patients. The first step for healthcare providers and professionals is to be aware of the increased CVD risk in patients with IMIDs. Reducing this risk is possible by a combined treatment of traditional CVD risk factors and optimal anti-inflammatory therapy. National guidelines should include recommendations for screening and management of CVD risk factors in these patients to make early interventions possible, especially in young patients with active disease. In general, CVD risk assessment and management (eg, determining target values for lipids and blood pressure) can be done according to the European Society of Cardiology and American Heart Association guidelines for CVD risk prevention. ${ }^{39}$ For RA, a multiplication factor of 1.5 should be applied to existing CVD risk prediction algorithms in accordance with the currently available evidence. ${ }^{50}$ For other IMIDs, a global CVD risk assessment according to existing algorithms is recommended, as there is insufficient evidence about additional methods (eg, a multiplication factor) to improve CVD risk prediction in these patients. Unfortunately, there are no IMIDspecific CVD risk prediction algorithms, and for RA the current CVD prediction methods are known to be inaccurate. The accuracy of existing CVD risk algorithms in predicting CVD in other IMIDs has not been investigated. In the absence of (IMID-specific) national recommendations, the European League Against Rheumatism recommendations for CVD risk management in inflammatory joint disorders could be used. Efforts should be made to investigate areas in which we lack knowledge, such as research on the exact pathways that lead to an increased CVD risk in chronic inflammatory states, CVD risk factors in men versus women and in non-Caucasians with IMIDs, randomised controlled trials investigating the effects of anti-inflammatory therapy on CVD risk, as well as research on gene expression profiles and single nucleotide polymorphisms that could aid in CVD risk stratification and possibly in finding new therapeutic targets. In addition, patients themselves should be made aware of their increased CVD risk and should be more involved in research and development of prevention strategies in this area.

\section{CONCLUSIONS}

IMIDs are associated with an increased CVD risk, which translates in increased healthcare cost and loss of quality of life in affected patients. This increased CVD risk is caused by a combination of an increased prevalence of traditional CVD risk factors and inflammation. Risk reduction is possible through early and effective management of CVD risk factors and optimal anti-inflammatory therapy aiming at-at least-low disease activity, but preferably disease remission. There is a need for a multidisciplinary effort to reduce CVD risk in these patients. Healthcare professionals, especially rheumatologists, cardiologists and general practitioners, but also patients themselves should be aware of this increased CVD risk and take timely precautions. There lies an evidence gap which needs to be filled in the future, and general practice guidelines need to be developed to reduce CVD risk in these patients.

\section{SUMMARY}

- Cardiovascular disease risk is markedly increased in immune-mediated inflammatory diseases, leading to excess mortality.

- Cardiovascular disease in immune-mediated inflammatory diseases is caused by a combination of traditional cardiovascular disease risk factors and enhanced independently by inflammation inherent to immune-mediated inflammatory diseases.

- Cardiovascular disease especially occurs during disease flares in undertreated patients.

- Clinicians and patients should both be aware of this increased cardiovascular disease risk and work together to timely intervene and prevent cardiovascular morbidity and mortality.

Contributors All authors substantially contributed to the following points of this manuscript: (1) conception or design of 
the work, or acquisition, analysis or interpretation of data for the work; (2) drafting the paper or revising it critically for important intellectual content; and (3) final approval of the version to be published. All authors are accountable for all aspects of the work in ensuring that questions related to the accuracy or integrity of any part of the work have been appropriately investigated and resolved.

Funding The authors have not declared a specific grant for this research from any funding agency in the public, commercial or not-for-profit sectors.

Competing interests None declared.

Patient and public involvement Patients and/or the public were not involved in the design, or conduct, or reporting, or dissemination plans of this research.

Patient consent for publication Not required.

Provenance and peer review Commissioned; externally peer reviewed.

Author note References which include a * are considered to be key references.

Open access This is an open access article distributed in accordance with the Creative Commons Attribution Non Commercial (CC BY-NC 4.0) license, which permits others to distribute, remix, adapt, build upon this work non-commercially, and license their derivative works on different terms, provided the original work is properly cited, appropriate credit is given, any changes made indicated, and the use is non-commercial. See: http:// creativecommons.org/licenses/by-nc/4.0/.

\section{ORCID iD}

Rabia Agca http://orcid.org/0000-0002-2477-0945

\section{REFERENCES}

1 Stolwijk C, Boonen A, van Tubergen A, et al. Epidemiology of spondyloarthritis. Rheum Dis Clin North Am 2012;38:441-76.

2 Bewtra M, Kaiser LM, TenHave T, et al. Crohn's disease and ulcerative colitis are associated with elevated standardized mortality ratios: a meta-analysis. Inflamm Bowel Dis 2013;19:599-613.

*3 Agca R, Heslinga SC, van Halm VP, et al. Atherosclerotic cardiovascular disease in patients with chronic inflammatory joint disorders. Heart 2016;102:790-5.

4 Sparks JA, Chang S-C, Liao KP, et al. Rheumatoid arthritis and mortality among women during 36 years of prospective followup: results from the nurses' health study. Arthritis Care Res 2016;68:753-62.

5 Aviña-Zubieta JA, Choi HK, Sadatsafavi M, et al. Risk of cardiovascular mortality in patients with rheumatoid arthritis: a meta-analysis of observational studies. Arthritis Rheum 2008;59:1690-7.

6 Haroon NN, Paterson JM, Li P, et al. Patients with ankylosing spondylitis have increased cardiovascular and cerebrovascular mortality: a population-based study. Ann Intern Med 2015;163:409-16.

7 Ogdie A, Yu Y, Haynes K, et al. Risk of major cardiovascular events in patients with psoriatic arthritis, psoriasis and rheumatoid arthritis: a population-based cohort study. Ann Rheum Dis 2015;74:326-32.

8 Feng W, Chen G, Cai D, et al. Inflammatory bowel disease and risk of ischemic heart disease: an updated meta-analysis of cohort studies. J Am Heart Assoc 2017;6:e005892. doi:10.1161/ JAHA.117.005892

9 Sun H-H, Tian F. Inflammatory bowel disease and cardiovascular disease incidence and mortality: a meta-analysis. Eur J Prev Cardiol 2018;25:1623-31.

10 Agca R, Heslinga M, Nurmohamed MT. Cardiac Diseases in Rheumatoid Arthritis. In: Atzeni F, ed. The heart in systemic autoimmune diseases. Elsevier Science, 2017: 227-50.

11 Wolfe F. The effect of smoking on clinical, laboratory, and radiographic status in rheumatoid arthritis. J Rheumatol 2000;27:630-7

12 Boyer J-F, Gourraud P-A, Cantagrel A, et al. Traditional cardiovascular risk factors in rheumatoid arthritis: a meta-analysis. Joint Bone Spine 2011;78:179-83.
13 Gonzalez A, Maradit Kremers H, Crowson CS, et al. Do cardiovascular risk factors confer the same risk for cardiovascular outcomes in rheumatoid arthritis patients as in non-rheumatoid arthritis patients? Ann Rheum Dis 2008;67:64-9.

14 Papagoras C, Markatseli TE, Saougou I, et al. Cardiovascular risk profile in patients with spondyloarthritis. Joint Bone Spine 2014;81:57-63.

15 Peters MJL, van Eijk IC, Smulders YM, et al. Signs of accelerated preclinical atherosclerosis in patients with ankylosing spondylitis. J Rheumatol 2010;37:161-6.

16 Kimhi O, Caspi D, Bornstein NM, et al. Prevalence and risk factors of atherosclerosis in patients with psoriatic arthritis. Semin Arthritis Rheum 2007:36:203-9.

17 Sundström B, Johansson G, Johansson I, et al. Modifiable cardiovascular risk factors in patients with ankylosing spondylitis. Clin Rheumatol 2014;33:111-7.

18 Doran MF, Brophy S, MacKay K, et al. Predictors of longterm outcome in ankylosing spondylitis. J Rheumatol 2003;30:316-20.

19 Parkes GC, Whelan K, Lindsay JO. Smoking in inflammatory bowel disease: impact on disease course and insights into the aetiology of its effect. J Crohns Colitis 2014:8:717-25.

*20 van Halm VP, Peters MJL, Voskuyl AE, et al. Rheumatoid arthritis versus diabetes as a risk factor for cardiovascular disease: a cross-sectional study, the CARRE investigation. Ann Rheum Dis 2009;68:1395-400.

21 Peters MJ, van der Horst-Bruinsma IE, Dijkmans BA, et al. Cardiovascular risk profile of patients with spondylarthropathies, particularly ankylosing spondylitis and psoriatic arthritis. Semin Arthritis Rheum 2004;34:585-92.

22 Gulati AM, Semb AG, Rollefstad S, et al. On the HUNT for cardiovascular risk factors and disease in patients with psoriatic arthritis: population-based data from the Nord-Trøndelag health study. Ann Rheum Dis 2016;75:819-24.

23 Han C, Robinson DW, Hackett MV, et al. Cardiovascular disease and risk factors in patients with rheumatoid arthritis, psoriatic arthritis, and ankylosing spondylitis. J Rheumatol 2006;33:2167-72

*24 Bigeh A, Sanchez A, Maestas C, et al. Inflammatory bowel disease and the risk for cardiovascular disease: does all inflammation lead to heart disease? Trends Cardiovasc Med 2020;30:463-9.

25 Panoulas VF, Douglas KMJ, Milionis HJ, et al. Prevalence and associations of hypertension and its control in patients with rheumatoid arthritis. Rheumatology 2007;46:1477-82.

26 Myasoedova E, Crowson CS, Kremers HM, et al. Lipid paradox in rheumatoid arthritis: the impact of serum lipid measures and systemic inflammation on the risk of cardiovascular disease. Ann Rheum Dis 2011;70:482-7.

27 Burger D, Dayer J-M. High-Density lipoprotein-associated apolipoprotein A-I: the missing link between infection and chronic inflammation? Autoimmun Rev 2002;1:111-7.

28 Semb AG, Holme I, Kvien TK, et al. Intensive lipid lowering in patients with rheumatoid arthritis and previous myocardial infarction: an explorative analysis from the incremental decrease in endpoints through aggressive lipid lowering (ideal) trial. Rheumatology 2011;50:324-9.

29 Toms TE, Panoulas VF, Douglas KMJ, et al. Are lipid ratios less susceptible to change with systemic inflammation than individual lipid components in patients with rheumatoid arthritis? Angiology 2011:62:167-75.

30 Liao KP, Solomon DH. Traditional cardiovascular risk factors, inflammation and cardiovascular risk in rheumatoid arthritis. Rheumatology 2013;52:45-52.

31 Estruch R, Ros E, Salas-Salvadó J, et al. Primary prevention of cardiovascular disease with a Mediterranean diet. N Engl J Med 2013;368:1279-90.

32 Sköldstam L, Hagfors L, Johansson G. An experimental study of a Mediterranean diet intervention for patients with rheumatoid arthritis. Ann Rheum Dis 2003:62:208-14.

33 Giles JT, Allison M, Blumenthal RS, et al. Abdominal adiposity in rheumatoid arthritis: association with cardiometabolic risk factors and disease characteristics. Arthritis Rheum 2010;62:3173-82

34 Binymin K, Herrick A, Carlson G, et al. The effect of disease activity on body composition and resting energy expenditure in patients with rheumatoid arthritis. J Inflamm Res 2011:4:61-6.

35 Summers GD, Metsios GS, Stavropoulos-Kalinoglou A, et al. Rheumatoid cachexia and cardiovascular disease. Nat Rev Rheumatol 2010;6:445-51. 
36 Durcan L, Wilson F, Conway R, et al. Increased body mass index in ankylosing spondylitis is associated with greater burden of symptoms and poor perceptions of the benefits of exercise. $J$ Rheumatol 2012;39:2310-4.

37 Jahnsen J, Falch JA, Mowinckel P, et al. Body composition in patients with inflammatory bowel disease: a population-based study. Am J Gastroenterol 2003;98:1556-62.

38 Moran GW, Dubeau M-F, Kaplan GG, et al. The increasing weight of Crohn's disease subjects in clinical trials: a hypothesis-generatings time-trend analysis. Inflamm Bowel Dis 2013;19:2949-56.

*39 Piepoli MF, Hoes AW, Agewall S, et al. 2016 European Guidelines on cardiovascular disease prevention in clinical practice: The Sixth Joint Task Force of the European Society of Cardiology and Other Societies on Cardiovascular Disease Prevention in Clinical Practice (constituted by representatives of 10 societies and by invited experts)Developed with the special contribution of the European Association for Cardiovascular Prevention \& Rehabilitation (EACPR). Eur Heart J 2016;37:2315-81.

40 Metsios GS, Stavropoulos-Kalinoglou A, Panoulas VF, et al. Association of physical inactivity with increased cardiovascular risk in patients with rheumatoid arthritis. Eur J Cardiovasc Prev Rehabil 2009;16:188-94.

41 Hernández-Hernández V, Ferraz-Amaro I, Díaz-González F. Influence of disease activity on the physical activity of rheumatoid arthritis patients. Rheumatology 2014;53:722-31.

42 Stavropoulos-Kalinoglou A, Metsios GS, Veldhuijzen van Zanten JJJCS, et al. Individualised aerobic and resistance exercise training improves cardiorespiratory fitness and reduces cardiovascular risk in patients with rheumatoid arthritis. Ann Rheum Dis 2013;72:1819-25.
43 Ford ES. Does exercise reduce inflammation? physical activity and C-reactive protein among U.S. adults. Epidemiology 2002;13:561-8.

44 Lemmey AB, Marcora SM, Chester K, et al. Effects of high-intensity resistance training in patients with rheumatoid arthritis: a randomized controlled trial. Arthritis Rheum 2009;61:1726-34.

45 Sveaas SH, Berg IJ, Provan SA, et al. Efficacy of high intensity exercise on disease activity and cardiovascular risk in active axial spondyloarthritis: a randomized controlled pilot study. PLoS One 2014;9:e108688.

46 Eckert KG, Abbasi-Neureither I, Köppel M, et al. Structured physical activity interventions as a complementary therapy for patients with inflammatory bowel disease - a scoping review and practical implications. BMC Gastroenterol 2019;19:115.

*47 Libby P, Ridker PM, Maseri A. Inflammation and atherosclerosis. Circulation 2002:105:1135-43.

48 Lindhardsen J, Ahlehoff O, Gislason GH, et al. The risk of myocardial infarction in rheumatoid arthritis and diabetes mellitus: a Danish nationwide cohort study. Ann Rheum Dis 2011;70:929-34.

49 Myasoedova E, Chandran A, Ilhan B, et al. The role of rheumatoid arthritis ( $r A$ ) flare and cumulative burden of RA severity in the risk of cardiovascular disease. Ann Rheum Dis 2016;75:560-5.

*50 Agca R, Heslinga SC, Rollefstad S, et al. EULAR recommendations for cardiovascular disease risk management in patients with rheumatoid arthritis and other forms of inflammatory joint disorders: 2015/2016 update. Ann Rheum Dis 2017;76:17-28.

51 El-Gabalawy H, Guenther LC, Bernstein CN. Epidemiology of immune-mediated inflammatory diseases: incidence, prevalence, natural history, and comorbidities. J Rheumato/ Supp/ 2010;85:2-10. 